\title{
Literatura infantil, teoria da mente e processamento de informação social
}

\author{
Histórias e desenvolvimento sociocognitivo
}

\author{
Marisa Cosenza Rodrigues \\ Paula Almeida de Oliveira \\ Jacqueline Silva Rubac \\ Aline Lima Tavares
}

\section{Resumo}

\begin{abstract}
Esta pesquisa objetivou identificar a ocorrência de termos/expressões que denotam estados mentais e analisar uma amostra de 100 livros de histórias infantis nacionais dirigidas a pré-escolares de 4 a 6 anos com foco no processamento de informação social. Os livros foram codificados a partir de três eixos de análise: via palavras e expressões no texto, via figuras; e presença de ironia e crença falsa na narrativa. $A$ análise dos termos mentais foi submetida ao julgamento de dois juízes e, posteriormente, ao teste de coeficiente de Spearman. Quanto ao processamento de informação social, a amostra de livros foi analisada considerando a ocorrência dos seis componentes de um programa estadunidense de redução do comportamento agressivo por meio de histórias infantis. Os resultados apontam a viabilidade da utilização dos livros infantis nacionais como recurso para promover o desenvolvimento sociocognitivo e prevenir comportamentos agressivos e anti-sociais no contexto educativo.
\end{abstract}

Palavras-chave: Desenvolvimento Sociocognitivo; Histórias Infantis; Psicologia Escolar/educacional

\section{Children's literature, theory of mind and social information processing}

\begin{abstract}
This research aimed to identify the occurrence of words/utterances that denotes mental states and also to analyze a sample of a 100 children's storybooks directed to pre-school children aged from 4 to 6 years based on social information processing approach. The books were codified according to three views of analysis: words/utterances in the text, pictures e presence of irony or false beliefs in the narrative. The analysis of mental words was submitted to judgment of two judges and later to the Spearman Coefficient test. In relation to the Social Information Processing approach the book sample was analyzed considering the occurrence of 6 components of an American program for the reduction of aggressive behavior through children's storybooks. The results point out the viability of using national storybooks as a resource to promote social cognitive development and prevent aggressive and anti-social behavior in educational settings.

Keywords: Social cognitive development; Children's storybooks; Educational Psychology
\end{abstract}

\section{Literatura infantil, teoría de la mente y procesamiento de información social}

\section{Resumen}

Esta investigación tuvo como objetivo identificar la ocurrencia de términos/expresiones que denotan estados mentales y analizar una muestra de 100 libros de historias infantiles nacionales dirigidas a pré-escolares de 4 a 6 años centrados en el procesamiento de información social. Los libros fueron codificados a partir de tres ejes de análisis: vía palabras y expresiones en el texto, vía figuras y presencia de ironía y creencia falsa en la narrativa. El análisis de los términos mentales fue sometido a la opinión de dos jueces y posteriormente al test de coeficiente de Spearman. En relación al procesamiento de información social, la muestra de libros fue analizada considerando la ocurrencia de los seis componentes de un programa estadounidense de reducción del comportamiento agresivo por medio de historias infantiles. Los resultados apuntan la viabilidad de la utilización de los libros infantiles nacionales como recurso para promover el desarrollo socio-cognitivo y prevenir comportamientos agresivos y antisociales en el contexto educativo.

Palabras clave: desarrollo socio-cognitivo, historias infantiles, psicología escolar/educacional. 


\section{Introdução}

No cenário da psicologia escolar contemporânea, alguns autores têm apontado novos paradigmas de atuação profissional (Andrada, 2005; Araújo \& Almeida, 2003; Guzzo, 200I; Maluf, 2003). Guzzo (200I) propõe transformações das práticas cristalizadoras acerca do desenvolvimento humano para estratégias que promovam a saúde e o bem-estar dos sujeitos, a mudança de foco do fracasso para o sucesso escolar, substituindo o paradigma da doença para o da saúde psicológica. Faz-se necessário o redimensionamento da prática dos psicólogos escolares e o empreendimento de uma atuação promotora de saúde psicológica e de desenvolvimento humano na educação que, segundo autores como Feldman (1994), Guzzo (200I) e Del Prette e Del Prette (2003), é cada vez mais importante tanto quanto urgente e possível em nosso meio, sendo um grande desafio a ser enfrentado pelos psicólogos escolares.

Vários esforços já podem ser evidenciados nesta direção. Rodrigues (2004, 2005), por exemplo, delimita estratégias possíveis de atuação para os psicólogos escolares, considerando teorias e modelos psicológicos de domínio específico, tais como a teoria da mente e do processamento de informação social. A autora, numa ótica preventiva e promotora da saúde psicológica, discute possíveis aplicações destes referenciais teóricos no contexto educativo a partir da utilização do recurso da leitura de histórias infantis, indicando a necessidade de pesquisas que possam subsidiar essa interface teórico-prática no contexto nacional como é o caso do presente trabalho.

\section{Teoria da Mente}

De acordo com Caixeta e Caixeta (2005), "teoria da mente é o nome que se dá à maneira como sentimos e entendemos a mente dos outros" (p.7). Considerando o foco predominante em pesquisas com crianças de 3 a 6 anos de idade, realizadas na década de 90 , atualmente os pesquisadores tendem a definir a teoria da mente de maneira mais específi- ca, como a área que se dedica a investigar a habilidade de crianças pré-escolares a fim de compreender seus próprios estados mentais e das outras pessoas, e de utilizarem esta informação para predizer suas ações e comportamentos (Dias, 1993; Feldman, 1992; Jou \& Sperb, 1999; Lourenço, 1992; Weelman, 199I). Maluf, Deleau, Panciera, Valério e Domingues (2004) complementam essa definição destacando como teoria da mente o entendimento que as crianças elaboram durante os primeiros anos de vida, a respeito da mente, isto é, a respeito das emoções, intenções, pensamentos e crenças das pessoas com quem convivem. Assim, ela é constituída por um campo recente de estudo e pesquisa interdisciplinar, incluindo etologistas, primatologistas, antropólogos, filósofos da mente, psicólogos cognitivistas e do desenvolvimento e especialistas em autismo. No Brasil, a área tem despertado interesse de vários estudiosos e pesquisadores, como demonstram os trabalhos de Jou e Sperb (1999) e Maluf e cols. (2004).

Do ponto de vista evolutivo, segundo Rodrigues (2004), pesquisas no contexto nacional a respeito da crença falsa', fundamentais nos estudos sobre teoria da mente, apontam que a compreensão desta nas crianças brasileiras já é aparente por volta dos cinco anos de idade. No entanto, a autora ressalta a necessidade de realização de mais pesquisas visando fomentar o desenvolvimento desta área do conhecimento psicológico, ainda pouco explorado na realidade brasileira. Maluf e cols. (2004) corroboram as afirmações da autora citada e ressaltam que

“...não encontramos na literatura brasileira estudos com enfoque longitudinal, nem estudos de intervenção, ambos com freqüência crescente na literatura internacional, devido às possibilidades que oferecem de maior compreensão do fenômeno e de intervenção positiva na realidade individual e social” (p. 82).

Sensíveis a possíveis aplicações desse referencial teórico, Flavel, Miller e Miller (1999) salientam que a

\footnotetext{
' Crença falsa pode ser definida como a capacidade de compreender que as pessoas podem ter crenças que são contraditórias e conflitantes com a realidade (Rodrigues, 2004).
} 
teoria da mente dos pré-escolares configura uma área de extrema relevância para a cognição social, constituindo uma base sólida para a compreensão das várias habilidades sóciocognitivas que as crianças em idade mais avançada vão precisar para interagir com os outros. Maluf e cols. (2004) ressaltam a importância de se compreender a mente do outro "tanto para psicólogos quanto para educadores dada as implicações e aplicações desse conhecimento nas mais diversas atividades voltadas para o favorecimento do desenvolvimento social e da aprendizagem escolar durante os primeiros anos de vida" (p. 53).

No plano internacional, alguns estudos fornecem subsídios que contribuem para a compreensão e promoção do desenvolvimento de uma teoria da mente na criança: conversações pais-filhos (Bretherton \& Beeghly, 1982; Dunn, Bretherton \& Munn, 1987), o número de irmãos (Perner, Ruffman \& Leekam, 1994), envolvimento em brincadeiras de faz-de-conta (Leslie, 1987; Lillard, 200I; Roazzi \& Santana, 1999) e pesquisas no contexto educativo (Astington \& Pelletier, 2000). De interesse para o presente trabalho são as pesquisas que utilizaram livros de histórias infantis como possível recurso para a compreensão dos estados mentais (Cassidy e cols, 1998; Dyer, Shatz \& Wellman, 2000). É consenso dentre esses autores que os livros de histórias para crianças pequenas pelo conteúdo do material textual que apresentam, pelo tipo de linguagem que utilizam e por centrarem suas ações e interações em pessoas ou animais personificados podem contribuir para a compreensão infantil de conteúdos relacionados à mente.

A partir dessa visão prospectiva dos livros infantis, Dyer e cols. (2000) realizaram um estudo minucioso, analisando 90 livros de histórias infantis publicados nos Estados Unidos com base nas referências voltadas para os estados mentais. Três eixos de análise foram considerados: via palavras e expressões, via figuras e por meio das situações irônicas encontradas no texto. Os resultados obtidos foram altamente favoráveis indicando que os livros apresentaram uma alta proporção de referências textuais para estados mentais. No tocante à análise das figuras contidas nos livros, os dados indicaram que, sozinhas, as figuras falharam ao representarem conceitos de esta- do mental, expressados no texto. Entretanto, figura e texto juntos continham ironia situacional em um terço dos livros analisados. Como assinalam os autores, os resultados sugerem que a informação relativa aos estados mentais foi amplamente expressada via palavras e ironia, permitindo a afirmação de que mesmo crianças muito novas se beneficiam com essa atividade na compreensão da mente.

Há dois estudos internacionais que investigaram a linguagem dos livros com referência aos estados mentais e que, em termos gerais, corroboram os dados obtidos por Dyer e cols. (2000), embora tenham empregado metodologia menos refinada. Um estudo de Ruther, publicado em 1997 e citado pelos autores Dyer e cols. (2000), analisou 30 livros de histórias para crianças de 2 a 6 anos de idade e encontrou também alta freqüência desses termos. A pesquisa de Cassidy e cols. (1998) analisou conceitos relativos ao conteúdo da teoria da mente em uma ampla amostra de 37I livros infantis publicados nos Estados Unidos. Os resultados encontrados indicaram que $78 \%$ dos livros continham linguagem voltada para os estados internos, $34 \%$ continham crenças falsas, e $43 \%$ continham descritores de personalidade. Os autores concluíram que conceitos da teoria da mente é parte integrante da literatura lida para a criança em idade préescolar.

A escassez de estudos mais amplos na literatura brasileira envolvendo livros e a compreensão dos estados mentais indica a necessidade de realizar investigações que possam fornecer contribuições para a seleção adequada de livros. Esses efetivamente podem ser utilizados no contexto educativo, caracterizando uma interface aplicada entre a psicologia do desenvolvimento e a psicologia escolar.

\section{Modelo do Processamento de Informação Social}

A orientação conceitual cognitiva que emergiu da perspectiva do processamento de informação ocupa lugar central na cognição social (Wyer \& Strull, 1994). Nesse sentido, o estudo do conhecimento social e dos processos cognitivos fornece uma chave para a compreensão do comportamento social e de seus fatores mediadores. Os modelos voltados para o 
processamento de informação social (Social Information Processing - SIP) derivam da abordagem do processamento de informação mais geral que se dedica a investigar como o conhecimento é organizado e processado.

Do ponto de vista da psicologia do desenvolvimento, a abordagem do processamento de informação procura oferecer uma compreensão explícita e minuciosa do que o sistema cognitivo de uma criança realmente faz quando está realizando uma tarefa ou em meio a um problema atual (online) (Flavell e cols., 1999). Os modelos do processamento de informação social enfatizam o papel ativo da cognição sobre a interação e adaptação social, procurando descrever o modo como as crianças processam a informação social e selecionam um comportamento nas situações do dia-a-dia. Os modelos que começaram a se desenvolver, em meados dos anos de 1980, no campo da cognição social focalizam os mecanismos que contribuem para o comportamento socialmente competente das crianças. $O$ foco é o ajustamento social bem como a compreensão dos mecanismos envolvidos na agressividade infantil, pressupondo-se que a compreensão e interpretação das situações pelas crianças influenciam o seu comportamento.

O modelo mais sistemático do processamento de informação social foi proposto por Dodge (1986) o qual obteve significativo apoio empírico (Yoon, Hughes, Archna \& Thompson, 1999). Após uma revisão crítica trazendo inovações conceituais, Dodge e Crick (1994) ampliaram o modelo propondo seis passos no processamento da informação social. Como explica Rodrigues (2005), de acordo com esse modelo, nos dois primeiros passos, a criança codifica e interpreta as pistas sociais oferecidas pelo ambiente fazendo uma leitura interna da situação social, há a interpretação e representação mental das pistas sociais de acordo com as informações disponíveis e armazenadas na memória. No terceiro passo, a criança passa a determinar e selecionar objetivos, metas pessoais e resultados desejados na situação tendo por base expectativas concretizadas em situações experienciadas no passado. No quarto passo, a criança constrói uma resposta acessando informações armazenadas na memória podendo também construir novas respostas a situações novas. Já o quinto passo compreende o processo de decisão da criança sobre o que fazer, envolvendo avaliação das respostas e alternativas possíveis, considerando sua adequação e expectativas quanto aos resultados esperados ou desejados do ponto-de-vista pessoal, social e moral. Finalmente no sexto e último passo, tem-se a resposta ou ação comportamental da criança. É oportuno ressaltar que Lemerise e Arsenio (2000) empreenderam um esforço de integração do fator emoção no modelo proposto por Dodge e Crick (1994).

Trabalhos na área de resolução de problemas interpessoais (Beelman, Pfingsten \& Losel, 1994) e baseados no enfoque do processamento de informação social (Guerra \& Slaby, 1990) mostram que quando as crianças são solicitadas a pensar antes de agir ou a justificar seu comportamento, torna-se mais provável a ocorrência de um processamento mental menos impulsivo, mais consciente e adequado diante de certas situações. Neste caso, situações que estimulem ou conduzam a criança a observar, pensar e avaliar possíveis conseqüências antes de agir ou reagir, nos mais diferentes contextos de desenvolvimento, podem contribuir para o aperfeiçoamento evolutivo do processamento de informação social. Em cada passo do modelo são descritos processos específicos passíveis de serem desenvolvidos e estimulados nas crianças, tornando o modelo proposto por Dodge e Crick (1994) referência importante para o psicólogo escolar/educacional.

Uma aplicação desse modelo, no contexto educativo, é apresentada por Teglasi e Rothman (200I) que desenvolveram um programa voltado para a redução da agressão infantil que associa a leitura e o relato de histórias ao processamento de informação social acima referido. Os autores tinham por objetivo ensinar alternativas de ação em situações de conflito entre crianças agressivas para reduzir o comportamento agressivo na escola. O programa, baseado na leitura de histórias desenvolvido pelos autores, durou 15 semanas e privilegiou dois preditores na exploração e discussão das histórias - levar a criança a pensar em soluções alternativas e pensar e prever conseqüências potenciais numa situação interpessoal. O trabalho envolveu pequenos grupos heterogêneos 
(4 a 6 anos) de crianças identificadas e não-identificadas como agressivas de duas escolas elementares norteamericanas envolvendo pré e pós-avaliação dos professores que indicaram as crianças mediante características de provocação, hostilidade e agressão. Os resultados mostraram diminuição de comportamentos anti-sociais e de externalização nos grupos de crianças não-identificadas como agressivas e, entre aquelas identificadas que tinham completado o programa, diminuição significativa de escores quando comparados com o grupo controle. Como salientam Dodge e Crick (1994), crianças agressivas têm dificuldade em registrar soluções relevantes para os problemas por apresentarem distorções no processamento das pistas sociais além de dificuldade para processar informações relativas às intenções e aos motivos dos outros.

De acordo com Teglasi e Rothman (200I), as histórias infantis constituem recurso que pode ser utilizado para organizar elementos importantes do processamento de informação social, na medida que "integram os vários componentes do modelo associando-os com o comportamento agressivo" (p. 75), inclusive nos aspectos relacionados com a emoção. Os autores apresentam uma descrição de como o programa de histórias, elaborado e implementado, liga os componentes da narrativa e o processamento de informação social: $O$ que está acontecendo? As crianças identificam o problema, fazendo um balanço do que está acontecendo externamente, considerando a perspectiva do personagem intimidador, da vítima e do espectador; $O$ que os personagens estão pensando e sentindo? As crianças também identificam o problema pela observação do que está ocorrendo no mundo íntimo de cada personagem envolvido na trama; exploram conexões entre sentimentos, intenções e interpretações dos personagens das situações externas; Quais são as intenções e metas dos personagens? Pensamentos e sentimentos dos personagens sobre uma situação em particular são discutidos em relação às suas intenções e metas no momento imediato e em termos temporais mais alongados, encorajando as crianças a clarificar suas próprias intenções e metas, na medida em que consideram os apuros e as situações vivenciadas pelos personagens; $O$ que os personagens alcançam com suas ações? Os resultados atuais e prováveis das decisões, planos e ações dos personagens da história são discutidos e explorados em relação às suas metas e intenções prévias; Como os personagens executam e monitoram os próprios comportamentos? Os personagens podem executar a ação intencionada e obter êxito ou serem mal sucedidos na tarefa. Nesse sentido, as razões devem ser observadas e discutidas; Quais as lições aprendidas? Teglasi e Rothman (200I) "assinalam que a solução efetiva de problemas requer a aplicação de lições de vida que são naturalmente aprendidas a partir da experiência" (p.77). O programa elaborado procura ampliar esse processo experiencial, por meio da exploração de detalhes da história, de interações grupais e do estabelecimento de relações com as experiências individuais dos participantes.

Considerando que a promoção de saúde pelo desenvolvimento de competências específicas constitui uma ferramenta importante na prevenção primária e que a idéia subjacente nas ações e intervenções é a de incrementar aspectos positivos do desenvolvimento do ser humano, a utilização de histórias para promover o desenvolvimento infantil nos domínios aqui ressaltados pode ser implementada como uma das estratégias dentro de um programa preventivo mais amplo e ser aplicada nas próprias salas de aula, ou em situações menos formais (Rodrigues, 2004, 2005). No contexto nacional, alguns esforços têm sido desenvolvidos nessa perspectiva cognitiva de atuação (Rodrigues, Abreu \& Carvalho, 2005).

O objetivo do presente estudo foi, portanto, identificar a ocorrência de termos e expressões denotando estados mentais, bem como, analisar com foco no processamento de informação social uma amostra de livros de histórias nacionais.

\section{Método}

A amostra de 100 livros nacionais para crianças de 4 a 6 anos foi selecionada mediante consultas ao Ministério da Educação, Fundação Nacional do Livro Infanto-Juvenil, Secretaria Estadual de Educação (MG) e catálogos de editoras de renome nacional na área da literatura infantil. 
No que tange à teoria da mente, foi utilizada metodologia semelhante àquela empregada por Dyer e cols. (2000). Com base nos estudos desses autores e na lista de termos denotando estados mentais, gerados por Bretherton e Beeghly (1982), obteve-se uma listagem de termos mentais que foram subdivididos em quatro categorias: termos emocionais, cognitivos, desejos e intenções, e avaliação moral e obrigação. Essa listagem categorizada foi utilizada como referência para a codificação dos termos e expressões mentais encontrados nos livros que foram investigados considerando-se três eixos de análise: codificação e freqüência dos termos e expressões mentais encontrados, de acordo com as quatro categorias anteriormente citadas; presença de ironia situacional e crença falsa; convergência entre figura e estado mental; gerando-se um instrumento para análise de cada livro.

De acordo com Dyer e cols. (2000), a ironia situacional encoraja e estimula o leitor a ir além da perspectiva que é imediatamente dada pela narrativa, fornecendo informação sobre mente e experiência nos diversos assuntos. No presente estudo, a ironia analisada foi aquela que se torna evidente no fim da história e a crença falsa foi categorizada pelo envolvimento do disfarce conjugado com a pretensão de enganar o outro, pela percepção equivocada da realidade e pela carência de informações; sendo categorizadas como presente ou ausente.

A análise da convergência entre figura e estado mental foi realizada considerando-se três figuras de cada livro (início, meio e fim). Nos livros com narrativas muito curtas ou muito pobres em termos mentais foi analisado o número de figuras de acordo com o número de páginas contendo termos ou expressões mentais independentes da parte da narrativa em que essa figura se localizava. Utilizou-se como referência nessa análise uma escala variando de 0 a 3 pontos: figura nada convergente ( 0 ponto), figura pouco convergente (I ponto), figura convergente (2 pontos) e expressiva convergência (3 pontos). Considerando os três eixos mencionados, os livros foram analisados por uma das pesquisadoras e por dois juízes. O primeiro eixo de análise (ocorrência de termos e expressões voltados para os estados mentais) foi sub- metido ao teste de coeficiente de correlação de Spearman (Levin, 1987). Os juízes e a pesquisadora, embasados pelo mesmo referencial, discutiram as discordâncias. A análise dos livros quanto à convergência entre figura e estado mental foi realizada considerando a média aritmética entre as notas atribuídas pelos juízes e a pesquisadora para cada livro analisado. A presença de ironia e crença falsa foi apurada considerando-se a indicação, por parte da pesquisadora e dos juízes, de ocorrência ou não.

Quanto ao processamento de informação social, a análise do conteúdo das narrativas foi realizada com base na estrutura do programa desenvolvido por Teglasi e Rothman (200I), considerando os seis componentes propostos anteriormente. Para facilitar a análise dos livros foram elaborados dois instrumentos. O primeiro foi utilizado para registrar quais os componentes do programa apareciam nas diferentes partes das narrativas (início, meio e fim), o qual incluiu uma escala geral de avaliação do livro envolvendo o número de componentes presentes e passíveis de serem explorados na narrativa. Livros que continham apenas um componente do modelo foram descritos como impróprios para análise com base no processamento de informação social, enquanto aqueles que atendiam dois componentes foram considerados com limitado repertório de pistas sociais. Livros que apresentaram três ou quatro componentes do modelo foram avaliados com número relevante de pistas sociais, respectivamente. Por fim, as narrativas, que contemplaram cinco ou todos os passos do modelo, foram consideradas ricas do ponto de vista do processamento de informação social. O segundo instrumento foi elaborado visando facilitar o registro do aparecimento dos componentes do programa proposto por Teglasi e Rothman (200I) considerando cada página do livro. $O$ instrumento visa, no plano aplicado, facilitar trabalhos posteriores tanto de psicólogos escolares quanto de outros profissionais interessados em utilizar o modelo do processamento de informação social associado aos livros infantis, analisados nesta pesquisa como recurso cognitivo de prevenção do comportamento agressivo na escola.

A análise baseada no processamento de informação social foi realizada com a leitura minuciosa de cada 
livro conjuntamente entre a pesquisadora e as bolsistas envolvidas a fim de obter a maior concordância possível quanto ao aparecimento, na narrativa, de cada componente do programa proposto por Teglasi e Rothman (200I).

\section{Resultados e Discussão}

Os resultados obtidos na análise da amostra dos livros infantis indicaram índice de correlação pelo teste do coeficiente de Spearman (pesquisadora e 2 juízes independentes) aproximado de $92 \%$. O índice de concordância para presença de ironia e crença falsa foi de $98 \%$. As correlações feitas para a categorização em relação a categorias de termos cognitivos, emocionais, desejos e intenções, e obrigação e avaliação moral foram, em sua grande maioria, significativas para o nível de 0,05.

A análise realizada indicou um alto índice de referências a estados mentais. $92 \%$ dos livros para crianças de 4 a 6 anos evidenciaram termos denotando estados mentais, sendo que destes, $22,8 \%$ contemplaram as 4 categorias de análise proposta (termos emocionais, cognitivos, desejos e intenções, avaliação moral e obrigação), 35,9\% contemplaram três categorias, 30,4\% apresentaram duas categorias e 10,9 $\%$ contemplaram apenas I categoria. Esses resultados corroboram os obtidos no estudo de Cassidy e cols. (1998) em que foi evidenciado um índice de $78 \%$ de referências a estados internos. Como também aqueles encontrados na pesquisa de Dyer e cols. (2000), o qual indicou que os livros estavam repletos de informações e termos voltados para os estados mentais, apresentando explícita referência para pensamentos, sentimentos e intenções dos personagens.

Nos livros analisados nesta pesquisa foram encontrados, no total, 1563 termos denotando estados mentais, incluindo as palavras cognatas, sendo que a categoria de termos mais freqüente foi a que denotava estados emocionais apresentando 633 palavras (41\%), dentre as quais várias eram termos cognatos (ex: assustar, assustado, assustando), seguido da categoria envolvendo estados cognitivos em que houve 612 palavras (39\%), desejo e intenção com 186
(I2\%) e avaliação moral e obrigação com apenas I 32 palavras (8\%). Agrupando os cognatos, evidenciaramse 213 tipos diferentes de termos denotando estados mentais; sendo que 126 (59\%) não constavam da listagem tomada como referência. Esse dado evidencia que um número expressivo de palavras foi encontrado nos livros nacionais refletindo possivelmente a diversidade da língua portuguesa que apresenta em seu vocabulário número bastante extenso de vocábulos se comparado ao da língua inglesa.

$\mathrm{Na}$ análise final foram registrados 94 tipos diferentes de palavras para estados emocionais desconsiderando-se os cognatos. Dentre os termos emocionais, o termo mais freqüente foi "gostar" com 42 referências $(6,6 \%)$. Esse achado corrobora os dados obtidos por Cassidy e cols. (1998) em que $80 \%$ dos livros analisados apresentaram predominância de termos e expressões denotando estados emocionais. Convergem também com o estudo de Dyer e cols. (2000) no qual também se evidenciou expressiva freqüência de termos emocionais. Considerando a convergência entre os termos cognatos, dentre os estados emocionais foram encontrados 27 termos $(28,5 \%)$ denotando estados emocionais positivos ( $p$. ex.: alegria, felicidade, diversão, adorar, sorrir), 56 termos $(59,5 \%)$ indicando estados emocionais negativos (p. ex.: tristeza, susto, medo) e 12 termos (I2\%) categorizados como neutros (p. ex.: "boquiaberta", saudade).

No que se refere aos estados cognitivos, foram identificados no total 612 palavras, envolvendo 72 tipos diferentes (por ex.: saber, pensar, achar, resolver, perguntar, esquecer...). Saber e seus cognatos (sabia, sabido, sabendo...) foi o termo mais freqüente com 99 referências a esse termo (16\%). É interessante notar que nos estudos de Bretherton e Beeghly (1982), saber também foi a palavra mais evocada por crianças de até 28 meses. De acordo com esses autores, os termos cognitivos aparecem mais tardiamente no vocabulário das crianças, pois "a criança pode ter uma vaga consciência do que os outros pensam, lembram e supõem, mas não podem associar o termo verbal correto com esses estados" (p. 916). É possível considerar que para crianças pré-escolares inferir pensamentos e crenças subjacentes é mais difí- 
cil que percepções, estados fisiológicos e emoções uma vez que os correlatos comportamentais tendem a ser mais aparentes. Nesse sentido, Dyer e cols. (2000) assinalam, embora se refiram a livros e não a conversações infantis, que é de especial interesse os livros de histórias infantis focalizarem mais referências aos estados cognitivos do que aos desejos, sugerindo que o foco central do livro deve visar àquilo que as crianças precisam saber ou aprender.

$\mathrm{Na}$ amostra de livros analisados foram encontrados 186 termos denotando desejo ou intenção, incorporando os termos cognatos foram identificados no total 12 tipos diferentes (por ex.: querer, procurar, pedir, vontade, desejo, "estar a fim"). Dentre esses termos, querer predominou com $58 \%$ sobre os demais com 107 referências a essa palavra. Frye (199I) afirma que o reconhecimento das intenções em outros permite à criança distinguir entre pessoas e objetos físicos. Pode-se considerar que a presença desses termos nas narrativas nacionais indica uma possível exploração contribuindo para o desenvolvimento infantil de uma teoria da mente, uma vez que, segundo Feinfield, Blacher e Baker (1999), por envolver planos e planejamentos, aprender sobre intenções e sua relação com os outros estados mentais e com o comportamento, constitui parte significativa do desenvolvimento geral da teoria da mente.

Do total de 1563 termos denotando estados mentais identificados nessa amostra de livros nacionais, foram identificados somente 132 termos denotando avaliação moral e obrigação. Agrupando os termos semelhantes foram encontrados 35 tipos diferentes de palavras tais como: obedecer, mandar, "ter que", castigo, ordem... Nessa categoria, o termo mais encontrado foi mandar com 25 referências (I8\%). Um aspecto importante a ser ressaltado, diz respeito ao caráter histórico dos livros infantis. Rodrigues (2004), com base em diversos autores, salienta que a literatura infantil no Brasil surgiu a partir de uma preocupação pedagógica marcada pela intenção de moralizar a criança. De acordo com Becker (200I), tal posicionamento tem se modificado, instaurando-se uma linguagem simples e dirigida diretamente às necessidades e fantasias da criança. Os dados obtidos nessa categoria de termos foram pouco expressivos
(8\%), refletindo possivelmente, essa tendência contemporânea de maior incorporação do lúdico na literatura infantil nacional.

No que se refere à convergência figura e estado mental, segundo a escala de avaliação utilizada, observou-se que $34 \%$ do total de livros apresentaram-se como totalmente convergente, $52 \%$ como convergente e $14 \%$ como pouco convergente. Ou seja, todos os livros apresentaram um índice de convergência, não sendo encontrada nenhuma figura totalmente divergente do(s) termo(s) mental(is) envolvido(s) na narrativa. Esses resultados divergem em parte daqueles obtidos por Dyer e cols. (2000), os quais indicaram que sozinhas as figuras falharam para representar de modo independente conceitos de estado mental expressados no texto. Para Camargo (1995), a análise da ilustração precisa focalizar os significados que decorrem não só do que a imagem representa, mas também de como ela o faz, expressando coerência entre imagem e narrativa; dado que a linguagem visual e textual dos livros infantis constitui-se de um único texto auxiliando o leitor a interagir com a palavra (Ramos \& Panozzo, 2004). O alto índice de convergência entre figura e estado mental encontrado neste estudo, refletem essa condição qualitativa constituindo razão adicional para serem utilizadas como recurso promotor no domínio aqui proposto.

No que se refere à ironia, dos 100 livros analisados nessa pesquisa, apenas em 12 foi constatada sua ocorrência. A presença da ironia foi identificada em dois diferentes contextos. $O$ primeiro, quando a informação era explícita, se restringindo aos eventos apresentados ao longo do texto. Nesse contexto, 3 livros denotavam surpresa e 5 livros continham um tom sarcástico. Por exemplo, no livro "O peixe Pixote" (editora Ática), a ironia pôde ser percebida quando foi verificado que o medo que o peixe sentia do escuro era conseqüência de nadar com seus olhos fechados. O segundo, quando a ironia só poderia ser interpretada por meio de um conhecimento prévio do leitor, 4 livros se adequaram a essa categoria, dentre eles "O sonho da vaca" (editora Ática), no qual a compreensão da ironia envolvia convenções sociais relacionadas à dinâmica familiar. Dado que a ironia, segundo Dyer e cols. (2000), estimula a compreensão da 
teoria da mente, os resultados pouco expressivos obtidos com essa amostra de livros, sugerem que esse aspecto deve ser mais explorado pelos autores nacionais.

A crença falsa foi evidenciada em II dos 100 livros (II\%); estando presente nos seguintes contextos: a) o envolvimento do disfarce conjugado com a pretensão de enganar o outro (presente em 3 livros); b) percepção equivocada da realidade (2 livros) e c) carência de informações, presente em 6 livros. Embora com menos freqüência, os resultados obtidos corroboram aqueles encontrados por Cassidy e cols. (1998), cuja presença de crença falsa foi identificada em $34 \%$ dos livros analisados. Esses autores discutem a maior frequiência de referências a estados internos em comparação a ocorrência de crença falsa justificando a possibilidade de ser mais fácil organizar uma narrativa sem crença falsa do que sem referências a estados mentais. Os dados obtidos sugerem a possibilidade de se focalizar, por meio das narrativas infantis, a capacidade infantil de compreensão da crença falsa.

A análise dos livros nacionais com base no modelo do processamento de informação social indicou resultados bastante satisfatórios considerando o conteúdo da narrativa e o atendimento aos componentes propostos por Teglasi e Rothman (200I). De acordo com a escala de avaliação utilizada $59 \%$ dos livros (59 livros) contemplaram cinco ou seis componentes do programa sendo avaliados de acordo com a escala em questão como narrativa rica quanto ao repertório de pistas sociais. Da amostra de livros analisados, $32 \%$ (32 livros) contemplaram três ou quatro componentes, sendo avaliados como narrativas com relevante repertório de pistas sociais. $6 \%$ dos livros contemplaram dois componentes sendo avaliados como narrativas com limitado repertório de pistas sociais e, apenas $3 \%$ dos livros contemplaram um único componente do programa sendo avaliados como livros com escasso repertório de pistas sociais. Considerando o conteúdo das narrativas e o foco nos componentes do processamento de informação social, evidenciou-se que, todas contemplaram algum desses componentes, não sendo encontrada nenhuma narrativa muito curta que inviabilizasse a análise com base no processamento de informação social. No conjunto, é expressiva a porcentagem de livros infantis $(75 \%)$ que apresentaram elevado repertório de pistas sociais (contemplaram 4, 5 ou 6 dos componentes do programa), o que permite indicar, no contexto nacional, a possível utilização dessas narrativas pelo psicólogo escolar considerando a vertente preventiva e promotora de competências cognitivas como foi realizado por Teglasi e Rothman (200I).

É importante destacar que em $96 \%$ da amostra é possível trabalhar com as crianças o primeiro componente do programa (“O que está acontecendo?") e em $91 \%$, o segundo componente ("O que os personagens estão pensando e sentindo?”). Esses dados reforçam que os livros analisados oferecem amplas oportunidades de discussão com as crianças sobre o(s) problema(s) apresentado(s) na narrativa possibilitando a avaliação, observação e interpretação das pistas sociais (situação externa) bem como do que está ocorrendo no mundo interno de cada personagem. Os dados relativos ao atendimento do segundo componente convergem com o elevado número de termos mentais ( 1245 termos), referentes à emoção e cognição, encontrados na presente pesquisa, permitindo caracterizar essa amostra de livros infantis como potencialmente fértil para a promoção do desenvolvimento sociocognitivo infantil. Vale salientar ainda que $71 \%$ dos livros atendem ao terceiro componente do programa que focaliza intenções e metas dos personagens, aspectos importantes do trabalho com as crianças que apresentam vieses e distorções cognitivas - tais como as agressivas (Del Prette \& Del Prette, 2005; Dodge \& Crick, 1994).

Nesse sentido, os resultados obtidos em relação ao quarto $(70 \%)$ e quinto itens do programa $(81 \%)$, envolvendo questionamentos sobre as estratégias encontradas pelos personagens bem como execução e monitoramento de suas ações e comportamentos acentuam a viabilidade de se trabalhar com as crianças, por meio desses livros, alternativas de ação em situação de conflito. Pode-se proporcionar às crianças agressivas, por exemplo, a formação de novas rotas para processar a informação social, contrastando com os modelos agressivos já vivenciados. Somente em $13 \%$ da amostra ficou evidenciado, de forma explíci- 
ta, o sexto componente, apontando que a presente amostra favorece pouco a resolução de problemas de forma eficaz considerando a organização de elementos por parte da criança por meio desse componente específico do processamento de informação social.

Teglasi e Rothman (200I) assinalam que as ilustrações das histórias indicam posturas e expressões faciais dos personagens podendo ser exploradas ao longo da narrativa. A alta convergência entre figura e estado mental encontrada nessa amostra de livros converge com os resultados também obtidos na perspectiva do processamento de informação social em que a ilustração torna-se fundamental por auxiliar a criança a identificar e avaliar o problema em relação ao mundo externo na observação das pistas sociais e em relação ao mundo interno de cada personagem, na exploração dos sentimentos e pensamentos deste.

De modo geral, os resultados aqui obtidos vão de encontro ao trabalho de Teglasi e Rothman (200I). Embora não apresentem resultados voltados especificamente para a amostra de histórias utilizadas em seu programa como objetivo, os resultados favoráveis ao desenvolvimento das crianças obtidos com essa intervenção assinalam as narrativas como um adequado recurso a ser explorado como estratégia na prevenção de problemas de comportamento infantil. Parte-se do pressuposto que as histórias por eles utilizadas apresentavam um rico potencial voltado para o processamento de informação social uma vez que o programa obteve êxito com crianças agressivas e não-agressivas.

\section{Considerações Finais}

O conceito de prevenção primária em saúde mental envolve ações que procuram evitar o surgimento de problemas psicológicos direcionados à construção de saúde psicológica, pelo desenvolvimento direto ou indireto de competências específicas que propiciem o bem-estar e qualidade de vida (Elias \& Marturano, 2004; Rodrigues, 2005). A tendência internacional mostrando resultados oriundos dos programas preventivos desenvolvidos em outros países incentiva a reflexão e o trabalho por novas formas de intervenção com base na mudança de paradigma, envolvendo uma prática profissional mais proativa no âmbito da psicologia escolar/educacional.

Nesta perspectiva, embora o presente estudo não constitua uma proposta de intervenção, os resultados gerados a partir da análise de livros infantis nacionais sob o enfoque da compreensão dos estados mentais e do processamento de informação social corroboram estudos internacionais fornecendo subsídios para a implementação de práticas cada vez mais preventivas e promotoras de saúde psicológica em nosso contexto. $O$ elevado repertório de pistas sociais e de expressões e termos voltados para estados mentais encontrados nos livros analisados fazem explícitas referências aos pensamentos, sentimentos, intenções e desejos dos personagens, indicando que as histórias infantis oferecem um rico e útil referencial para que sejam discutidos e explorados aspectos sociocognitivos relevantes.

A presente investigação demonstra que os livros de histórias infantis por constituírem um recurso barato e de fácil acesso podem contribuir para fundamentar o trabalho do psicólogo escolar - e também do próprio professor da educação infantil - na perspectiva das ações preventivas centradas no indivíduo sendo uma proposta de atuação mais adequada considerando as condições econômicas e educacionais limitadoras da realidade sul americana.

\section{Referências}

Andrada, E. G. C. (2005). Novos paradigmas na prática do psicólogo escolar. Psicologia Reflexão e Crítica, 18, 196- 199.

Araújo, C. M. M., \& Almeida, S. F. C. (2003). Psicologia escolar institucional: desenvolvendo competências para uma atuação relacional. Em S. F. C. de Almeida (Org.), Psicologia escolar: ética e competências na formação e atuação profissional (pp. 5982). Campinas: Alínea.

Astington, J. W., \& Pelletier, J. (2000). A linguagem da mente seu papel no ensino e na aprendizagem. Em D. R. Olson \& N. Torrance (Orgs.) Educação e Desenvolvimento Humano (pp.4895I0). Porto Alegre: Artmed. 
Becker, C. D. (200I). História da literatura infantil brasileira. Em J. A. Saraiva (Org.), Literatura e Alfabetização: do plano do estudo ao plano da ação (pp. 35-4I). Porto Alegre: Artmed.

Beelman, A., Pfingsten, V., \& Losel, F. (1994). Effects of training social competence in children: A meta-analysis of recent evaluation studies. Journal of Clinical Child Psychology, (23), 260-27I.

Bretherton, I., \& Beeghly, Y. M. (1982). Talking about internal states: The acquisition of an explicity Theory of Mind. Developmental Psychology, 18, 906-921.

Caixeta, M., \& Caixeta, L. (2005). A teoria da mente: aspectos psicológicos, neurológicos, neuropsicológicos e psiquiátricos. Campinas: Átomo.

Camargo, L. (1995). Ilustração do livro infantil. Belo Horizonte: Lê.

Cassidy, K. W., Ball, L. V., Rourke, M. T., Wermer, R. S., Feeny, N., Chu, J. Y., Lutz, D. J., \& Perkins, A. (1998). Theory of mind concepts in children's literature. Applied Psycholinguistics, 19, 463-470.

Del Prette, A., \& Del Prette, Z. A. P. (2003). Aprendizagem sócioemocional na escola e prevenção da violência: questões conceituais e metodologia da intervenção. Em A. Del Prette \& Z. A. P. Del Prette (Orgs.), Habilidades sociais, desenvolvimento e aprendizagem: Questões conceituais, avaliação e intervenção (pp. 83-127). Campinas: Alínea.

Del Prette, Z. A. P., \& Del Prette, A. (2005). Psicologia das habilidades sociais na infância: teoria e prática. Petrópolis: Vozes.

Dias, M. G. B. B. (1993). O desenvolvimento do conhecimento da criança sobre a mente. Psicologia: Teoria e Pesquisa, 9, 587-600.

Dodge, K.A. (1986). A social information processing model of social competence in children. In. M. Perlmutter (ed.), The Minnsesota Symposium on Child Psychology, vol. 18 (pp. 77125) Hillsdale: Earlbaum.

Dodge, K. A., \& Crick, N. R. (1994). A review and reformulation of social information-processing mechanisms in children's social adjustment. Psychological Bulletin, II5(I), 74-I0I.

Dunn, J., Bretherton, I., \& Munn, P. (1987). Conversations about feeling states between mothers and their young children. Developmental Psychology, 23(I), I32-39.

Dyer, J. R., Shatz, M., \& Wellman, H. M. (2000). Young children's storybooks as a source of mental state information. Cognitive Development, 15(I), 17-37.
Elias, L. C. S., \& Marturano, E. M. (2004). Habilidades de solução de problemas interpessoais e a prevenção dos problemas de comportamento em escolares. Em E. M. Marturano, M. B. M. Linhares \& S. R. Loureiro (Orgs.), Vulnerabilidade e proteção: indicadores na trajetória de desenvolvimento do escolar (pp. 197-2 I5). São Paulo: Casa do Psicólogo.

Feinfield, K. A., Blacher J., \& Baker B. L. (1999). Leaving or launching? Continuing family involvement with children and adolescents in placement. American Journal on Mental Retardation, 104, 452-465.

Feldman, C. F. (1992). The new theory of theory of mind. Human Development, 35, I07-I 17.

Feldman, N. (1994). De prevención a promoción: un desafio latinoamericano. Em ABRAPEE/PUC - Campinas (Org.), Anais do XVII ISPA Coll. e II Congresso Nacional de Psicologia Escolar (pp. 85-88). Campinas: Átomo

Flavel, J. H., Miller, P. H., \& Miller, A. S. (1999). Desenvolvimento Cognitivo. (C. Dornelles, Trad.). ( $3^{\mathrm{a}}$ ed.). Porto Alegre: Artmed. (Trabalho original publicado em língua inglesa em 1993).

Frye, D. (1991). The origins of intention in infancy. Em D. Frye \& C. Moore (Orgs.), Children's theories of mind: mental states and social understanding (pp. I5-38). Hillsdale: Erlbaum

Guerra, N. G., \& Slaby, R. G. (1990). Cognitive mediators of aggression in adolescent offenders: 2. Intervention. Developmental Psychology, 26, 269-277.

Guzzo, R. S. L. (200I). Saúde psicológica, sucesso escolar e eficácia da escola: Desafios do novo milênio para a psicologia escolar. Em Z. A. Del Prette (Org.), Psicologia Escolar e Educacional: Saúde e Qualidade de Vida (pp. 25-42). Campinas: Alínea.

Jou, G. I., \& Sperb, T. M. (1999) Teoria da Mente, diferentes abordagens. Psicologia: Reflexão e Crítica, I2(2), 287-306.

Lemerise, E. A., \& Arsênio, W. F. (2000). Na integrated model processes and cognition in social information processing. Child Development, 7 I(I), I07-I8.

Leslie, A. M. (1987). Pretense and representation in infancy: the origins of “Theory of Mind”. Psychological Review, 94, 4I 2-26.

Levin, J. (1987). Estatística Aplicada a Ciências Humanas (2a ed.). São Paulo: Harbra.

Lillard, A. S. (200I). Pretend play as twin earth: a socialcognitive analysis. Developmental Review, 2 I (4), 495-53I.

Lourenço, O. (1992). Teorias da mente na criança e o desenvolvimento de crenças falsas: Falsas de quem? Análise Psicológica, 4, 431-442. 
Maluf, M. R. (2003). O psicólogo escolar e a educação: uma prática em questão. Em Z. A. Del Prette (Org.), Psicologia escolar e educacional, saúde e qualidade de vida: explorando fronteiras (pp. 59-7I). Campinas: Alínea.

Maluf, M. R., Deleau, M., Panciera, S. D. P., Valério, A., \& Domingues, S. F. S. (2004). A teoria da mente: mais um passo na compreensão da mente das crianças. Em M. R. Maluf (Org.), Psicologia educacional: questões contemporâneas (pp. 09-222) São Paulo: Casa do Psicólogo.

Perner, J., Ruffman, T., \& Leekam, S. R. (1994). Theory of mind is contagious: you catch it from your sibs. Child Development, $65,1228-1238$.

Ramos, F. B., \& Panozzo, N. S. P. (2004). Entre a ilustração e a palavra: buscando pontos de ancoragem. Especulo: Revista de Estudios Literarios, 26, ano IX.

Roazzi, A., \& Santana, S. M. (1999). Teoria da Mente: efeito da idade, do sexo e do uso de atores animados e inanimados na inferência de estados mentais. Psicologia: Reflexão e Critica, I2(2), 307-330.

Rodrigues, M. C. (2004). Concepções docentes pré-escolares sobre teorias da mente e sóciocognitivas aplicadas. Tese de doutorado, Pontifícia Universidade Católica de Campinas, Campinas.
Rodrigues, M. C. (2005). Prevenção na escola: um enfoque cognitivo-social. Em M. M. P. E. Mota (Org.) Psicologia: interfaces com a educação e a saúde (pp. I I-30). Juiz de Fora: Editora UFJF.

Rodrigues, M. C., Abreu C., \& Carvalho, C. G. (2005). Histórias infantis e prevenção da agressividade: um enfoque cognitivo. Revista Brasileira de Extensão Universitária/ Fórum de Pró-Reitorias de Extensão, 3(2), 62.

Teglasi, H., \& Rothman, L. (200I). STORIES: A ClassroomBased Program to Reduce Aggressive Behavior. Journal of School Psychology, 39(I), 7I-94.

Wellman, H. M. (I99I). From desires to belief: acquisition of a theory of mind. Em A. Whiten (Org.), Natural theories of mind (pp. 19-38). Oxford: Blackwell.

Wyer, R. S., \& Strull, T. K. (1994). Handbook of social cognition (vol. I). Hillsdale: Erlbaum.

Yoon, J. S., Hughes, J. N., Archna, G., \& Thompson, B. (1999). Social cognition in aggressive children: a metaanalytic review. Cognitive and Behavioral Practice, 6, 320-33I.

Recebido em: 14/05/2006

Revisado em: 16/1 1/2006

Aprovado em: 28/02/2007

Sobre as autoras

Marisa Cosenza Rodrigues (rodriguesma@terra.com.br)) é Doutora em Psicologia pela PUC/Campinas-SP e docente do Departamento de Psicologia da Universidade Federal de Juiz de Fora.

Paula Almeida de Oliveira (paulapsi@yahoo.com.br) é Graduanda em Psicologia na Universidade Federal de Juiz de Fora Bolsista de Iniciação Científica do CNPq/PIBIC

Jacqueline Silva Rubac (jac_rubac@yahoo.com.br) é Graduanda em Psicologia na Universidade Federal de Juiz de Fora - Bolsista de Iniciação Científica BIC/PROPESQ-UFJF

Aline Lima Tavares (estrelinha.alima@bol.com.br) é Graduanda em Psicologia na Universidade Federal de Juiz de Fora PROVOQUE/PROPESQ-UFJF

Endereço para correspondência

Marisa Cosenza Rodrigues

Endereço: Praça Jarbas de Lery Santos n 37/apto. 103 - São Mateus - 36.016.390 - Juiz de Fora - MG 